\title{
Effect of copper on the adsorption of $p$-nitrophenol onto soils
}

\author{
Zhi-guo Pei ${ }^{\text {a }}$, Xiao-quan Shan ${ }^{\text {a,* }}$, Bei Wen ${ }^{\text {a }}$, Shuzhen Zhang ${ }^{\text {a }}$, \\ Liangguo Yan ${ }^{\mathrm{a}}$, Shahamat U. Khan ${ }^{\mathrm{b}}$ \\ a State Key Laboratory of Environmental Chemistry and Ecotoxicology, Research Center for Eco-Environmental Sciences, \\ Chinese Academy of Sciences, P.O. Box 2871, Beijing 100085, China \\ ${ }^{\mathrm{b}}$ Department of Chemistry and Biochemistry, MSN 3E2, George Mason University, 4400 University Drive, \\ Fairfax, VA 22030-4444, USA
}

Received 4 November 2004; accepted 27 May 2005

The adsorption of p-nitrophenol onto soils decreased in the presence of copper due to its competition for the adsorption sites.

\begin{abstract}
The effect of copper on adsorption of $p$-nitrophenol on two typical Chinese soils was investigated using a batch-equilibration method. Adsorption experiments were carried out when both copper and p-nitrophenol were adsorbed simultaneously, and when copper was previously adsorbed on soils. It was observed that adsorption of $p$-nitrophenol decreased with increasing copper concentrations thereby indicating a competition between copper and p-nitrophenol for occupying the adsorption sites on soils. Moisture increased the hydrated sphere and the acidity of water surrounding the cation, which further reduced the adsorption of $p$-nitrophenol. Fourier transform infrared spectroscopy study provided the direct evidence for the coordination of $p$-nitrophenol sorbed by soils with metal cation in $n$-hexane system. It was observed that the perturbations included a red shift of the $\nu_{\text {asym }}$ (NO) band, a concomitant blue-shift of the $\nu_{\mathrm{sym}}(\mathrm{NO})$ band and a blue-shift of $\mathrm{C}-\mathrm{N}$ band when compared with the infrared spectra obtained from water solution.
\end{abstract}

(C) 2005 Elsevier Ltd. All rights reserved.

Keywords: Adsorption; Soil; p-Nitrophenol; Copper

\section{Introduction}

In recent years considerable attention has been given to the fate of nitroaromatic compounds in the environment (Li et al., 2003; Zhu et al., 2000; Weissmahr et al., 1999). These compounds are widely used as pesticides, explosives, solvents, and intermediates in the synthesis of dyes (Weissmahr et al., 1997). Many of these

\footnotetext{
* Corresponding author. Tel.: +86 10 62923560; fax: +86 10 62923563

E-mail addresses: xiaoquan@mail.rcees.ac.cn,xq_shan1@yahoo. com.cn (X.-quan Shan).
}

compounds and their transformation products are considered of significant toxicological concern. For example, $p$-nitrophenol may reach the human being as a hydrolytic product during the degradation of several organophosphorus pesticides when present in food commodities.

Adsorption of nitroaromatic compounds mainly depends on the nature and position of the substituents on the aromatic ring as well as the exchangeable cations and the type of clays and their charge present in soil. Greater adsorption of nitroaromatic compounds by clays has been attributed to the formation of an electron donor-acceptor (EDA) complex, in which polarized 
aromatic rings parallel to the basal surfaces accept electrons from the siloxane oxygen to form the complex (Haderlein et al., 1996; Weissmahr et al., 1998; Haderlein and Schwarzenbach, 1993). Subsequently, Boyd et al. (2001) also observed that the adsorption of such compounds decreased due to the increased electron-releasing abilities of meta- and para-substituents on nitrobenzene. This observation was consistent with the EDA complex formation mechanism. However, Plemenschikov and Leszczynski (1999) challenged the EDA complex formation hypothesis. They studied 1,3,5trinitrobenzene (TNB) siloxane complex and found no electronic evidence for EDA complexation. In their study, the high affinity of 1,3,5-TNB for a model siloxane surface was attributed to the attractive Coulombic and van der Waals' forces between the surface and the planar structure of organic ligand. In addition to the proposed EDA complex formation mechanism, smectite clays may also adsorb neutral organic molecules by hydrophobic interactions (Laird and Fleming, 1999). Adsorption of nitroaromatic compounds was also related to the types and hydration characteristics of exchangeable cations (Johnston et al., 2001, 2002; Sheng et al., 2002; Saltzman and Yariv, 1975). For weakly hydrated cations (e.g., $\mathrm{K}^{+}$ and $\mathrm{Cs}^{+}$), the combined size of the cations and associated water molecules does not occupy all of the available space. Thus the portion of adsorption sites "available" for nitroaromatics sorption is expected to be relatively large resulting in a greater sorption. For cations with higher hydration energies (e.g., $\mathrm{Na}^{+}$and $\mathrm{Mg}^{2+}$ ), the space available in the interlamellar region would be correspondingly small because of the large hydrated radii of the cations. In addition, adsorption of nitroaromatic compounds was noted to be influenced by the different types of clays and was also affected by the different type and positions of substituents on the aromatic ring. Johnston et al. (2001) used Fourier transform infrared (FTIR) spectroscopy to demonstrate the formation of interlayer cation $-\mathrm{NO}_{2}$ complexation especially in $\mathrm{K}^{+}$and $\mathrm{Cs}^{+}$-smectites.

Heavy metals and organic contaminants coexist in soil. Several studies have been undertaken to investigate the adsorption and desorption on soil of either heavy metals (Liu and Richard, 2000; Düring et al., 2003; Mulligan et al., 1999) or organic contaminants (Gimsing et al., 2004b; Pusino et al., 2003) separately. However, little attention has been given to determine the effect of heavy metals on the adsorption of organic contaminants on soils. Similarly not much is known about the adsorption of heavy metals on soil as affected by organic contaminants (Maqueda et al., 1998; Gimsing et al., 2004a; Morillo et al., 1994, 1997, 2000, 2002). Adsorption and desorption of copper on montmorillonite were affected by the presence of a cationic pesticide chlordimeform (Maqueda et al., 1998). The effect was evaluated when both adsorbates were adsorbed simultaneously and when the pesticide was previously adsorbed on montmorillonite. Copper adsorption decreased when both adsorbates were adsorbed simultaneously, indicating a competition between copper and chlordimeform for interlamellar positions. Morillo et al. (1994, 1997, 2000, 2002) studied the mutual influence of glyphosate and copper adsorption on montmorrillonite and soil. Glyphosate adsorption on montmorillonite decreased in the presence of $\mathrm{Cu}$ in solution or adsorbed on the mineral. This is attributed to the formation of $\mathrm{Cu}$-glyphosate complexes that have a lower tendency to be adsorbed on montmorillonite than the free glyphosate. However, these workers also found that the presence of $\mathrm{Cu}$ enhances the adsorption of glyphosate on soil.

The objective of present study was to examine the effect of copper on the adsorption of $p$-nitrophenol on two typical Chinese soils namely Jiangxi and Heilongjiang soils, with different soil characteristics. The adsorption of $p$-nitrophenol from $n$-hexane and FTIR data were used to reveal the mechanism involved in elucidating the effect of copper on the adsorption of p-nitrophenol.

\section{Materials and methods}

\subsection{Soil characteristics}

The soils used in this study were collected from Jiangxi Province (southern China) and Heilongjiang Province (northern China). These are two typical Chinese soils with various physicochemical properties. Soil samples were air-dried, ground and screened through a $1-\mathrm{mm}$ nylon fiber sieve to remove stone, plant roots and other large particles, and stored in plastic bags. Soil suspension $\mathrm{pH}$ was measured at a soil to water ratio of $1: 1(\mathrm{w} / \mathrm{v})$. Organic carbon content in soils was determined by the Walkley-Black's method (Nelson and Sommers, 1982). Amorphous Fe-, Al- and Mn-oxides were determined by ammonium oxalate extraction methods (McKeague and Day, 1966). Crystalline Fe-, Al- and Mn-oxides were determined by the oxalate-ascorbic acid extraction method of Shuman (1982). The characteristics of the soils are shown in Table 1. Crystalline clay minerals were also analyzed by X-ray diffraction (XRD). The clay minerals of Jiangxi soil were dominated by kaolinite, limonite, goethite, with minor concentrations of hematite and gibbsite. In Heilongjiang soil, the clay minerals contained greater concentrations of illite, chlorite, and small amounts of kaolinite.

Nitrogen specific surface area (SSA) of soils was estimated by using a micromeritics Flowsorb II surface area analyzer, and by applying the Brunauer-EmmetTeller (BET) equation to sorption of $\mathrm{N}_{2}$ at a relative partial pressure of 0.3 at $77 \mathrm{~K}$. 
Table 1

Characteristics of soils

\begin{tabular}{|c|c|c|}
\hline & Jiangxi soil & Heilongjiang soil \\
\hline Sand $(\%)$ & 19.5 & 9.8 \\
\hline Silt $(\%)$ & 18.7 & 62.8 \\
\hline Clay $(\%)$ & 42.4 & 27.4 \\
\hline $\mathrm{pH}$ & 5.3 & 7.3 \\
\hline $\mathrm{CEC}\left(\mathrm{cmol} \mathrm{kg}^{-1}\right)$ & 14.7 & 32.7 \\
\hline Organic matter $(\%)$ & 0.66 & 6.86 \\
\hline \multicolumn{3}{|l|}{$\mathrm{Fe}(\%)$} \\
\hline Crystal. & 1.55 & 1.40 \\
\hline Amorp. & 0.24 & 0.47 \\
\hline \multicolumn{3}{|l|}{$\mathrm{Al}(\%)$} \\
\hline Crystal. & 1.36 & 1.58 \\
\hline Amorp. & 0.27 & 0.34 \\
\hline $\operatorname{Mn}\left(\mathrm{mg} \mathrm{kg}^{-1}\right)$ & 40.0 & 326 \\
\hline $\mathrm{DOC}\left(\mathrm{mg} \mathrm{kg}^{-1}\right)$ & 226 & 891 \\
\hline BET surface area $\left(\mathrm{m}^{2} \mathrm{~g}^{-1}\right)$ & 31.7 & 19.4 \\
\hline
\end{tabular}

\subsection{Reagents}

$p$-Nitrophenol ( $\left.p-\mathrm{NO}_{2}-\mathrm{C}_{6} \mathrm{H}_{4}-\mathrm{OH}, 97 \%\right)$ was purchased from Beijing Xingjin Company and used directly without further purification. Its solubility in water was $16000 \mathrm{mg} \mathrm{l}^{-1}$ with a $\mathrm{p} K_{\mathrm{a}}$ value of $7.15 . \mathrm{Cu}\left(\mathrm{NO}_{3}\right)_{2} \cdot 3 \mathrm{H}_{2} \mathrm{O}$ was of guarantee reagent grade (Beijing Chemicals, China). Methanol used was of HPLC grade.

\subsection{Competitive sorption between $\mathrm{Cu}$ and p-nitrophenol}

In the adsorption experiments, $\mathrm{NaNO}_{3}$ was used as soil background electrolyte because of its environmental implications and minimum probability of complexes formation. Various concentrations of $p$-nitrophenol and $\mathrm{Cu}$ were added to $0.4 \mathrm{~g}$ of soils in $20 \mathrm{ml}$ of $0.01 \mathrm{M}$ $\mathrm{NaNO}_{3}$ and $0.1 \mathrm{gl}^{-1} \mathrm{NaN}_{3}$ in $50 \mathrm{ml}$ glass centrifuge tubes sealed by Teflon-lined screw caps. Each competitive adsorption experiment was repeated in triplicate. The concentrations of $p$-nitrophenol and $\mathrm{Cu}$ used in the competitive adsorption ranged from 0.72 to $21.6 \mathrm{mM}$ and 0 to $2.0 \mathrm{mM}$, respectively. The suspension was rotated continuously for $24 \mathrm{~h}$ at room temperature $\left(23 \pm 1{ }^{\circ} \mathrm{C}\right)$ to ensure complete adsorption. The suspension was then centrifuged at $1667 \mathrm{~g}$ for $20 \mathrm{~min}$ to separate liquid and solid phases, and $1 \mathrm{ml}$ of supernatant was used for the analysis of $p$-nitrophenol by HPLC.

In order to determine the competitive adsorption of $\mathrm{Cu}$ with $p$-nitrophenol, several portions of $20 \mathrm{ml}$ of $0.01 \mathrm{M}$ $\mathrm{NaNO}_{3}$ and $0.1 \mathrm{~g}^{-1} \mathrm{NaN}_{3}$ solutions containing various concentrations of $p$-nitrophenol were added to $0.4 \mathrm{~g}$ soil, and the suspension was shaken for $12 \mathrm{~h}$. Different amounts of $\mathrm{Cu}$ solution were then added to the suspensions to make the initial $\mathrm{Cu}$ concentrations as 0 , $0.1,0.5$ and $2.0 \mathrm{mM}$, respectively. The suspension was shaken for an additional $12 \mathrm{~h}$. The centrifugation procedure and collection of supernatant for HPLC analysis were the same as described above.

\subsection{Adsorption of p-nitrophenol from n-hexane}

A portion of $4.0 \mathrm{~g}$ soils was dispersed in $4.0 \mathrm{mM}$ $\mathrm{Cu}\left(\mathrm{NO}_{3}\right)_{2}$ solution $(200 \mathrm{ml})$. The suspensions were rotated continuously for $24 \mathrm{~h}$ at room temperature to ensure complete adsorption. After reaching equilibrium, the suspension was centrifuged, and the supernatant was removed. Distilled water $(50 \mathrm{ml})$ was used to wash the residue soils in order to remove excess of $\mathrm{Cu}\left(\mathrm{NO}_{3}\right)_{2}$. The soils treated or untreated with $\mathrm{Cu}$ solution are referred here $\mathrm{Cu}$-soil and soil, respectively. The $\mathrm{Cu}$-soil and soil were oven-dried at $105{ }^{\circ} \mathrm{C}$ for $96 \mathrm{~h}$ to remove moisture. The oven-dried soils were stored in a desiccator prior to use. An aliquot of $20 \mu \mathrm{l}$ distilled water was added to the oven-dried soils $(0.4 \mathrm{~g})$, and the moistened soil was subsequently ground thoroughly to make the distribution of water homogeneously. The grounded soil was placed in $50 \mathrm{ml}$ glass tubes, capped with Teflon-lined screw caps, and stored in a desiccator prior to use. The partially hydrated soils and another portion of ovendried soils were suspended in $20 \mathrm{ml}$ of $n$-hexane containing various concentrations of $p$-nitrophenol in $50 \mathrm{ml}$ glass centrifuge tubes. The suspensions were rotated continuously for $24 \mathrm{~h}$ at room temperature $\left(23 \pm 1{ }^{\circ} \mathrm{C}\right)$ to reach equilibrium. The suspensions were then centrifuged at $1667 \mathrm{~g}$ for $20 \mathrm{~min}$ to separate liquid and solid phases. Aliquots of the supernatants $(10 \mathrm{ml})$ were dried under a gentle stream of nitrogen. A portion of $2 \mathrm{ml}$ of methanol was added into the residue in order to dissolve the compound of interest. The extract was filtered with acrodisk $(0.25 \mu \mathrm{m})$ and $1 \mu \mathrm{l}$ of filtrate was injected into the liquid chromatograph.

\subsection{FTIR measurements}

Infrared spectra were obtained on a Perkin-Elmer GX2000 Fourier transform infrared (FTIR) spectroscopy equipped with deuterated triglycine (DTGS) and mercury-cadmium-telluride (MCT) detectors, a $\mathrm{KBr}$ beam splitter and a sample bench purged with dry air. The resolution for the FTIR spectra was $2.0 \mathrm{~cm}^{-1}$, and a total of 64 scans was collected for each spectrum. The self-supporting soil films were prepared from soil suspensions. To obtain the soil suspensions, $20 \mathrm{ml}$ aliquots of an aqueous suspension containing both $p$-nitrophenol and $\mathrm{Cu}$ sorbed on Jiangxi soil were passed through a $0.45 \mu \mathrm{m}$ hydrophilic polyethersulfone membrane $(\phi=25 \mathrm{~mm})$ on a Millipore holder. Due to the small adsorption amount of $p$-nitrophenol in the presence of copper, the concentration of $p$-nitrophenol in solution was increased to $72.0 \mathrm{mM}$ to ascertain IR spectra. The resulting deposits on the filters of soil- $-p$-nitrophenol- $\mathrm{Cu}$ were allowed to be freeze-dried overnight and were removed from the filter by employing a knife edge. To obtain $\mathrm{Cu}$-soil sample from $n$-hexane, $20 \mathrm{ml}$ supernatant 
solution was removed and the soil-p-nitrophenol- $\mathrm{Cu}$ was freeze-dried and stored in a desiccator prior to use.

\subsection{Analysis}

The concentrations of $p$-nitrophenol were determined by HPLC (Agilent 1100 HPLC) fitted with a diode array detector (DAD) at the maximum adsorption wavelength of $317 \mathrm{~nm}$, and an extended polar selectivity reversedphase column $(15 \mathrm{~cm} \times 4.6 \mathrm{~mm}$ i.d. $)$. Isocratic elution was performed at a flow rate of $0.7 \mathrm{ml} \mathrm{min}{ }^{-1}$, the mobile phase was methanol:water $(60 \%: 40 \%)$. Controls consisted of soils and electrolyte solution but without $p$-nitrophenol. The amounts of $p$-nitrophenol adsorbed were calculated from the differences between the initial and the final equilibrium concentrations. The recoveries of $p$-nitrophenol following the adsorption procedure without soils were $>98 \%$. Under the experimental conditions described $p$-nitrophenol showed a single HPLC peak at the retention time of $6.5 \mathrm{~min}$.

\section{Results and discussion}

\subsection{Adsorption time}

The adsorption of $p$-nitrophenol $(10.8 \mathrm{mM})$ on two soils versus equilibrium time is presented in Fig. 1. Although the adsorption reached equilibrium in $4 \mathrm{~h}$, a $24 \mathrm{~h}$ period was used to ensure complete equilibrium in the subsequent experiments. The results indicated that the sorption of $p$-nitrophenol was very rapid within the first $4 \mathrm{~h}$. The adsorption of $p$-nitrophenol on Heilongjiang soil was lower than that on Jiangxi soil.

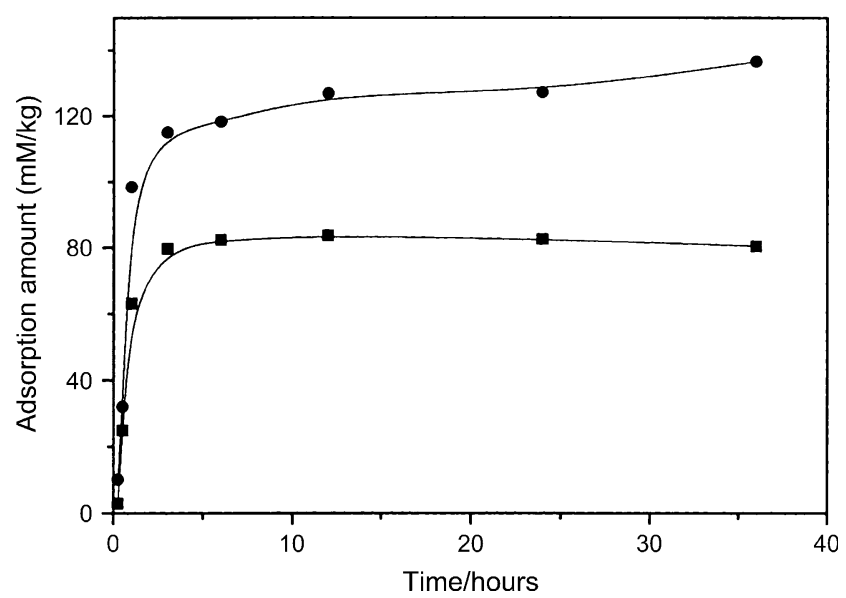

Fig. 1. Adsorption of $p$-nitrophenol versus equilibrium time by ( Heilongjiang soil; (-) Jiangxi soil. Equilibrium concentration of p-nitrophenol: $10.8 \mathrm{mM}$.

\subsection{Effect of $p H$ on $K_{d}$}

The adsorption of $p$-nitrophenol by soils was studied at various $\mathrm{pH}$ values. For the ionizable $p$-nitrophenol a strong $\mathrm{pH}$ dependence of the apparent $K_{\mathrm{d}}$ value was observed in the $\mathrm{pH}$ region corresponding to the $\mathrm{p} K_{\mathrm{a}}$ of the compound. The adsorption of $p$-nitrophenol onto two soils increased significantly from $\mathrm{pH} 2.5$ to 4 followed by a plateau over the $\mathrm{pH}$ range of $4-6$ and then the adsorption of $p$-nitrophenol rapidly decreased from $\mathrm{pH} 6$ to 8 (Fig. 2). The ionic fraction of $p$-nitrophenol ion $\left(\varphi_{\text {ions }}\right)$ can be calculated from:

$\varphi_{\text {ions }}=1 /\left[1+10^{\left(\mathrm{p} K_{\mathrm{a}}-\mathrm{pH}\right)}\right]$

Obviously, $\varphi_{\text {ions }}$ increases as the $\mathrm{pH}$ value increased. Considering $\mathrm{p} K_{\mathrm{a}}$ of 7.15 of $p$-nitrophenol, it appears that $p$-nitrophenol was present in neutral form when $\mathrm{pH}$ was less than 6 . However, it was present in the form of the dissociated anionic species when $\mathrm{pH}$ of equilibrium solution was higher than 8 . The small $K_{\mathrm{d}}$ of $p$-nitrophenol at higher $\mathrm{pH}$ values could be explained by electrostatic repulsion between the reactive surface site and the negatively charged $p$-nitrophenol molecule. The protons present in the aquatic system at $\mathrm{pH}$ lower than 4 will compete with $p$-nitrophenol for binding to the adsorption sites of soils. Therefore, the $K_{\mathrm{d}}$ value of $p$ nitrophenol is expected to decrease slightly at lower $\mathrm{pH}$.

\subsection{Competitive adsorption}

Competitive adsorption of $p$-nitrophenol and copper was evaluated when both adsorbates were adsorbed on Heilongjiang and Jiangxi soils simultaneously. The results are shown in Fig. 3a and b. The adsorption of p-nitrophenol onto Heilongjiang and Jiangxi soils decreased with the increase of copper concentrations

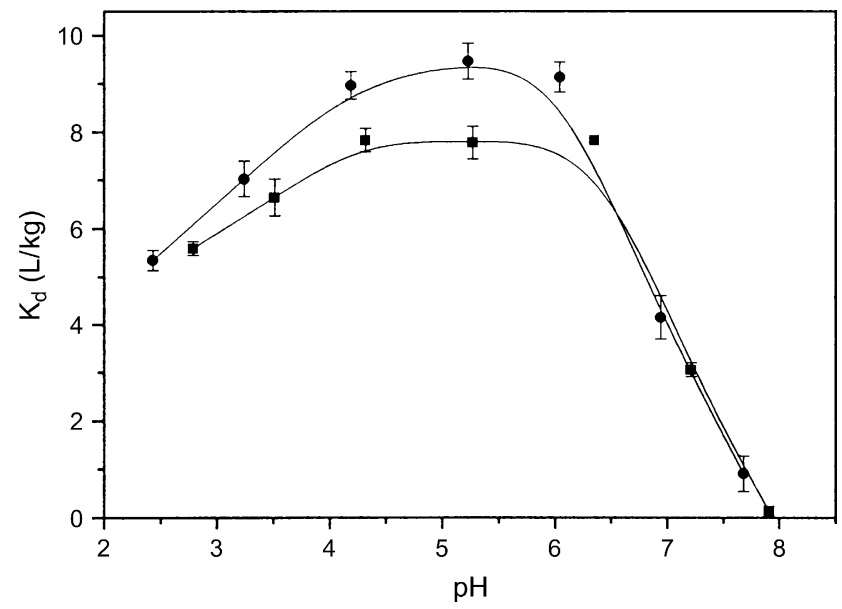

Fig. 2. Effect of equilibrium solution $\mathrm{pH}$ on $K_{\mathrm{d}}$ values of $p$-nitrophenol on Heilongjiang (ם) and Jiangxi $(\bullet)$ soil $(n=3): 0.4 \mathrm{~g}$ soil, $20 \mathrm{ml}$ of $0.01 \mathrm{M} \mathrm{NaNO}_{3}$, initial concentration of $10.8 \mathrm{mM}$ p-nitrophenol. 
from 0 to $2.0 \mathrm{mM}$. Almost no adsorption of $p$-nitrophenol in Jiangxi soil was observed when the $\mathrm{Cu}$ concentrations were greater than $0.5 \mathrm{mM}$. In contrast, copper had a relatively smaller suppression effect on the adsorption of $p$-nitrophenol on Heilongjiang soil.

$p$-Nitrophenol adsorption isotherms in the presence of copper can be described by a constant distribution coefficient as expressed by the following equation:

$K_{\mathrm{d}}=C_{\mathrm{sorb}} / C_{\mathrm{aq}}$

where $C_{\text {sorb }}$ and $C_{\mathrm{aq}}$ are the concentration of $p$ nitrophenol in soil (e.g., $\mathrm{mM} \mathrm{kg}^{-1}$ ) and in solution (e.g. $\mathrm{mM}^{-1}$ ), respectively. The competition of copper with $p$-nitrophenol for adsorption is reflected by the diminishing $K_{\mathrm{d}}$ values from 10.9 to 2.3 for Heilongjiang soil and from 18.3 to 0.01 for Jiangxi soil when the copper concentrations increased from 0 to $2.0 \mathrm{mM}$.

To determine whether copper can compete with $p$-nitrophenol for adsorption sites, a series of experiments were conducted. The two soils were first equilibrated with $p$-nitrophenol for $12 \mathrm{~h}$ and then copper solutions were added to the equilibrated suspension to make the initial copper concentrations of $0.1,0.5$ and $2.0 \mathrm{mM}$. The suspension was further equilibrated for an additional $12 \mathrm{~h}$ (Fig. $3 \mathrm{c}$ and d). It was found that the competitive adsorption between $p$-nitrophenol and copper was quite similar as indicated by the simultaneous adsorption of both adsorbates. This is due to the fact that copper with positive charge has stronger adsorption affinity than $p$-nitrophenol for adsorption sites on soils. Thus, $\mathrm{Cu}^{2+}$ can compete with $p$-nitrophenol for the same adsorption sites, even when $p$-nitrophenol was previously adsorbed on soils. This suggests that the addition of copper to soils would release the adsorbed $p$-nitrophenol from soils, a phenomenon that could be considered of great environmental importance.

Haderlein and Schwarzenbach (1993) and Haderlein et al. (1996) also observed similar effects of exchangeable cations on adsorption of nitroaromatic compounds. In the presence of strongly hydrated cations (e.g., $\mathrm{Na}^{+}$, $\mathrm{Mg}^{2+}$, etc.), no significant specific adsorption of nitroaromatic compounds was observed, while for more weakly hydrated cations (e.g., $\mathrm{K}^{+}, \mathrm{Cs}^{+}$, etc.), the adsorption of nitroaromatic compounds were greatly increased.

Fourier transform infrared (FTIR) linear dichroism measurements indicated that the adsorbed substituted nitroaromatic molecules were oriented coplanar to the siloxane surface of clay minerals (Johnston et al., 2002). The parallel orientation of nitroaromatic molecules relative to the clay mineral layers manifests a requirement for adsorption domains of sufficient size on the siloxane

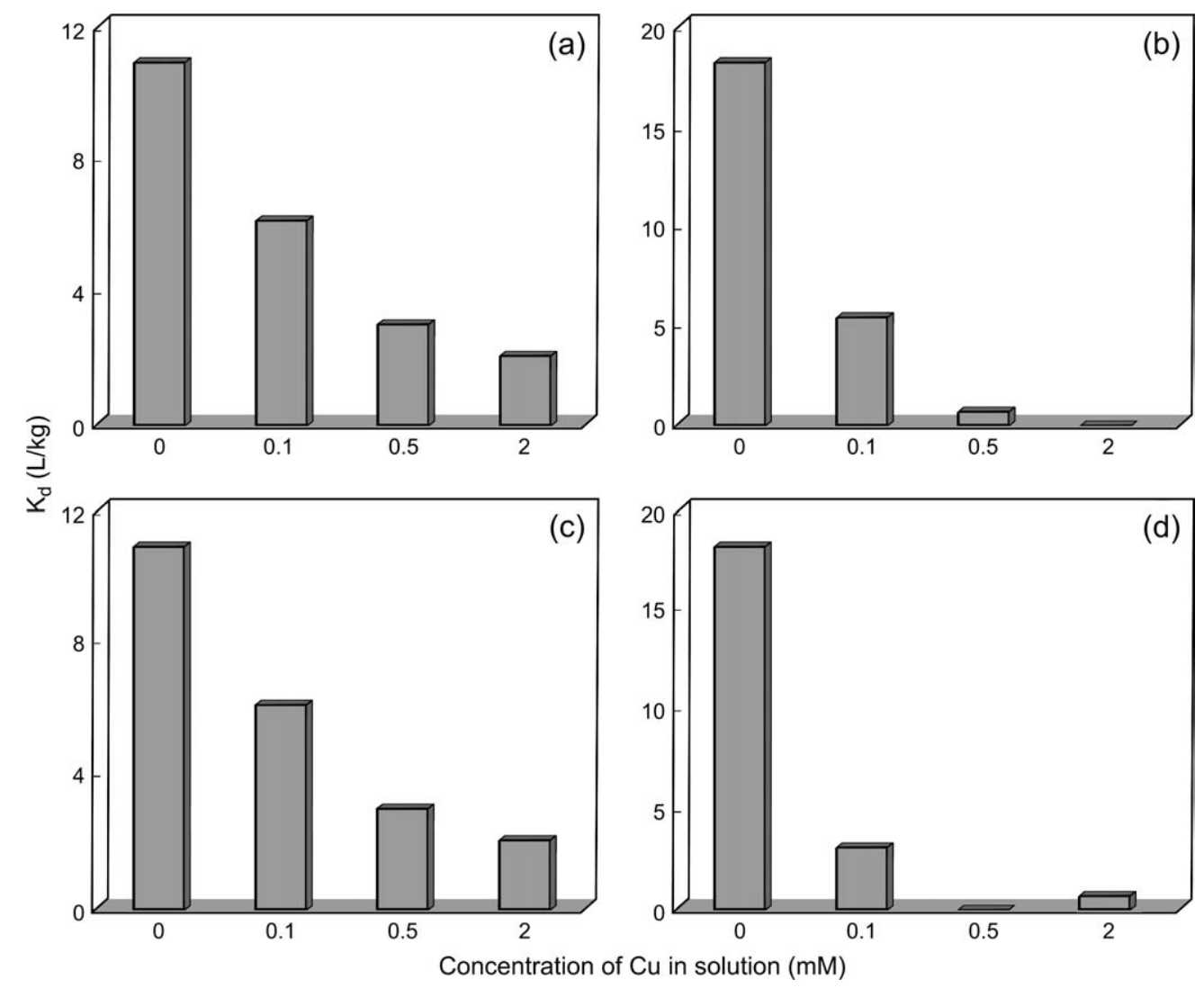

Fig. 3. Effect of different concentration of $\mathrm{Cu}$ on adsorption constants ( $K_{\mathrm{d}}$ values) of $p$-nitrophenol. $p$-Nitrophenol and $\mathrm{Cu}$ were added simultaneously: (a) Heilongjiang soil, (b) Jiangxi soil; p-nitrophenol was adsorbed previously: (c) Heilongjiang soil, (d) Jiangxi soil. 
surfaces between cations. In this study, the larger sizes of copper with a high hydrated energy $2100 \mathrm{~kJ} \mathrm{~mol}^{-1}$ may obscure a greater portion of the siloxane surfaces and shrink the size of the effective adsorption domains so that much less adsorption sites were available to accommodate $p$-nitrophenol molecules.

As shown in Fig. 3, adsorption of p-nitrophenol on highly-negative charged Heilongjiang soil was considerably less than that on low-negative charged Jiangxi soil. The characteristics of soils are listed in Table 1. Two mechanisms may be responsible for this phenomenon. First, the low charge of Jiangxi soil decreased the hydrated cations adsorbed thereby providing larger adsorption domains for $p$-nitrophenol, which was consistent with report of Sheng et al. (2002). Second, Jiangxi soil has greater surface area as compared with Heilongjiang soil, which means that Jiangxi soil can provide more site-specific adsorption for $p$-nitrophenol.

\subsection{Adsorption of p-nitrophenol in n-hexane}

To validate the hypothesis stated above, a further study was performed on the adsorption of $p$-nitrophenol from $n$-hexane on dried and partially hydrated soils $(10 \%$ water) in the absence and presence of $\mathrm{Cu}$. The results are shown in Fig. 4.

Freundlich equation (solid line) fit the adsorption isotherms (solid square, circle and triangle, Fig. 4):

$Q=K_{\mathrm{f}} C^{n}$

where $Q$ is the amount of $p$-nitrophenol adsorbed by soil, $C$ is the equilibrium concentration, $n$ is a constant of the isotherm curvature, and $K_{\mathrm{f}}$ is the Freundlich adsorption coefficient, an index of sorption capacity of soils.

The Freundlich adsorption coefficients are listed in Table 2. The adsorption capacity of $p$-nitrophenol decreased from 396.2 to 59.9 , and from 2489.4 to 131.5 when dried Jiangxi and Heilongiiang soils were hydrated with $10 \%$ water, respectively. The addition of exogenous copper further decreased the adsorption capacity of $p$-nitrophenol. The adsorption capacity of Jiangxi and Heilongjiang soils followed the order: dried soil $>$ dried soil with simultaneously addition of exogenous copper (afterwards it was referred to as $\mathrm{Cu}$ soil) $>$ hydrated soil $>$ hydrated soil with addition of exogenous copper (afterwards it was referred to as hydrated $\mathrm{Cu}$-soil). The adsorption of $p$-nitrophenol onto soils from $n$-hexane solvent was greater than that from water (Fig. 3), which could be partially attributed to the interaction of $p$-nitrophenol with both solvent and sorbent (Banat et al., 2000). Water solubility of p-nitrophenol is high $(115 \mathrm{mM})$ due to its hydrogen bonding between water and $p$-nitrophenol molecules, which is promoted by the dipole moment of $1.8 \mathrm{D}$ for water and $5.67 \mathrm{D}$ for $p$-nitrophenol. Because of the non-polar property of $n$-hexane, its interaction with $p$ nitrophenol is very weak. Accordingly, the solubility of $p$-nitrophenol in $n$-hexane is limited $(0.62 \mathrm{mM})$ compared with that in water. To achieve adsorption, the interaction between $p$-nitrophenol and soils should be stronger than that between $p$-nitrophenol and solvents. Saltzman and Yariv (1976) also found that with increasing polar character of solvent, the amount of adsorbed parathion decreased in accordance with the dielectric constants of these solvents (hexane, 1.89; water, 80.37). $p$-Nitrophenol is adsorbed on negatively charged surfaces through hydrogen bonding and/or charge transfer complexes.

The adsorbed amount of $p$-nitrophenol on partially hydrated soils was greater than that on partially hydrated $\mathrm{Cu}$-soils, which can be ascribed to the high polarity of $\mathrm{Cu}$. The electronegativity of $\mathrm{Cu}$ is 1.9 , which makes the dissociation of $\mathrm{H}$ more readily from soil minerals and water molecules associated with $\mathrm{Cu}$. The high acid strength of the $-\mathrm{OH}$ group of $p$-nitrophenol does not favor the formation of $\mathrm{H}$-bond with the waterassociated $\mathrm{Cu}$ because the highly polarizing $\mathrm{Cu}$ increased the ability of donoring proton. The acidity of water molecules coordinated with metal cations was also

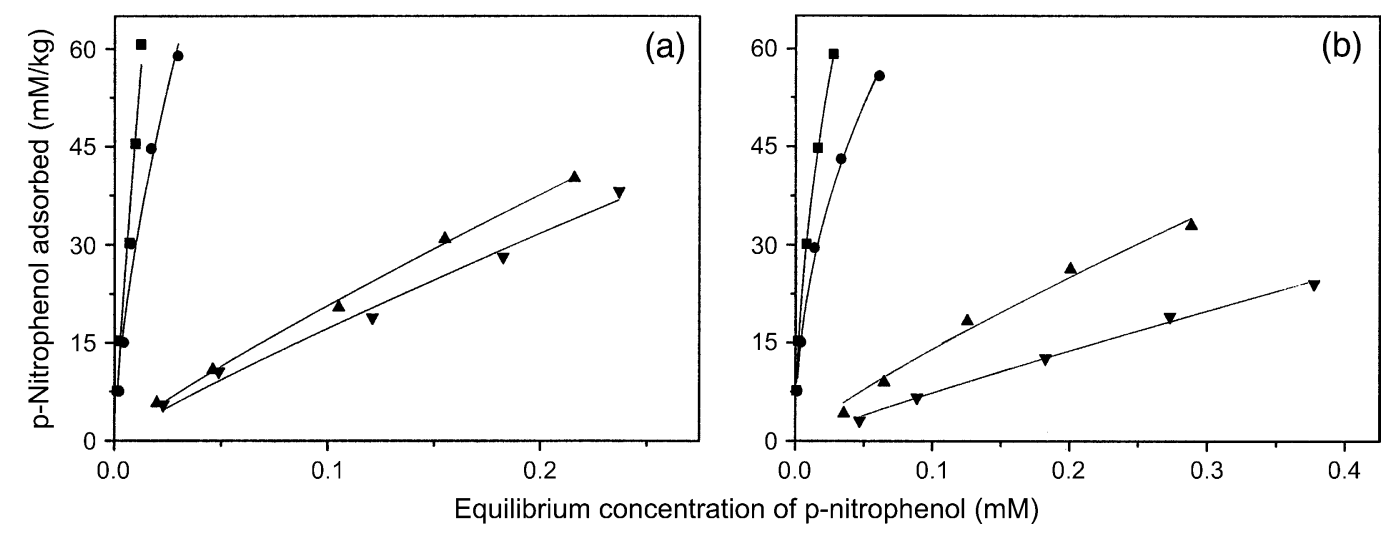

Fig. 4. Equilibrium sorption isotherms of $p$-nitrophenol from $n$-hexane on dried and partially hydrated soils (10\% water). (a) Heilongjiang soil; (b) Jiangxi soil. ( $\mathbf{\square})$ dried soil, ( $)$ dried Cu-soil, ( $\mathbf{\Delta})$ hydrated soil, ( $\mathbf{\nabla})$ hydrated Cu-soil. 
Table 2

Freundlich constants and correlation coefficients for $p$-nitrophenol adsorption on different adsorbents from $n$-hexane $(n=3)$

\begin{tabular}{|c|c|c|c|c|c|c|}
\hline \multirow[t]{2}{*}{ Adsorbent } & \multicolumn{3}{|c|}{ Jiangxi soil } & \multicolumn{3}{|c|}{ Heilongjiang soil } \\
\hline & $K_{\mathrm{f}}$ & $n$ & $R$ & $K_{\mathrm{f}}$ & $n$ & $R$ \\
\hline Dried soil & 396.2 & 0.530 & 0.99 & 2489.4 & 0.858 & 0.99 \\
\hline Dried soil- $\mathrm{Cu}$ & 213.2 & 0.474 & 0.98 & 579.1 & 0.641 & 0.99 \\
\hline Hydrated soil & 96.9 & 0.839 & 0.99 & 150.8 & 0.860 & 0.99 \\
\hline Hydrated soil-Cu & 59.92 & 0.913 & 0.99 & 131.5 & 0.883 & 0.99 \\
\hline
\end{tabular}

evaluated by Pusino et al. (2004). Furthermore, due to the addition of water, the ion radii of $\mathrm{Cu}$ increased from 0.72 to $6.0 \AA$. The large hydrated sphere of $\mathrm{Cu}$ occupied more space thus less adsorption sites were "available" for $p$-nitrophenol sorption. On the other hand, the large hydrated sphere was unfavorable to the interaction between $\mathrm{Cu}$ and the $-\mathrm{NO}_{2}$ group of $p$-nitrophenol.

It is evident from Fig. 4 that the adsorption of $p$-nitrophenol on two dried soils was slightly higher than that on two dried $\mathrm{Cu}$-soils. This appears to be due to the addition of $\mathrm{Cu}$ that occupied several adsorption sites and thus reduced the adsorption of $p$-nitrophenol. Johnston et al. (2002) suggested that the sorption of nitroaromatic compounds is attributed to two types of surface interaction: non-specific van der Waals' interactions between the neutral portion of the organic guest species and the clay siloxane surface; and the site-specific interactions between cations and organic substituents carrying partial negative atomic 'charge. Although $\mathrm{Cu}$ can also interact with $-\mathrm{OH}$ or $-\mathrm{NO}_{2}$ of $p$-nitrophenol, Fig. 4 indicated that the interaction is slightly weak compared to the nonspecific interaction.
FTIR spectroscopy was used to study the molecular scale interaction of nitroaromatic compound with sorbent. The vibrational modes of the $-\mathrm{NO}_{2}$ groups are sensitive to the charge of their local environment, which can be used to study the local environment of the soil surface.

When $\mathrm{Cu}$ cation is adsorbed on soils in $n$-hexane system, the $-\mathrm{NO}_{2}$ group of $p$-nitrophenol apparently coordinates directly to metal cation and to the residual polarized water molecules surrounding these cations. The interaction of the $-\mathrm{NO}_{2}$ substituent with interlayer $\mathrm{Cu}$ ion induced a blue-shift of the $\nu_{\text {sym }}(\mathrm{NO})$ band position from $1337 \mathrm{~cm}^{-1}$ for $\mathrm{Cu}$-soil in water solution to $1344 \mathrm{~cm}^{-1}$ in $n$-hexane. A concomitant shift in the opposite direction of the $\nu_{\text {asym }}$ (NO) band from 1516 to $1514 \mathrm{~cm}^{-1}$ was observed. The shifts were consistent with the observations reported by Johnston et al. (2001). Due to the electron-withdrawing property of $\mathrm{Cu}$ cation, the $\mathrm{C}-\mathrm{N}$ bonds are somewhat strengthened (shortened, with more double-bond character) in the $\mathrm{NO}_{2}-\mathrm{Cu}$ complex compared with the isolated, and uncomplexed $p$-nitrophenol molecules. This causes the $\mathrm{C}-\mathrm{N}$ stretching components in the complexes to increase in frequency from 1384 to $1389 \mathrm{~cm}^{-1}$. In addition, the blue-shift is also reinforced by electrostatic repulsion between $\mathrm{Cu}$ cation and the partial positive charge of $\mathrm{N}$ center. As shown by Boyd et al. (2001), the asymmetric $-\mathrm{NO}_{2}$ modes are dominated by the $\mathrm{N}-\mathrm{O}$ components, while the potential energy distribution of the symmetric $-\mathrm{NO}_{2}$ modes is comprised of not only $\mathrm{N}-\mathrm{O}$ stretching components, but also $\mathrm{C}-\mathrm{N}$ stretching components. Thus the blue-shift of $\nu_{\text {sym }}(\mathrm{NO})$ band to higher frequency was partly due to the strengthened $\mathrm{C}-\mathrm{N}$ bond upon complexation. Therefore, the shifts observed in Fig. 5 for the $-\mathrm{NO}_{2}$

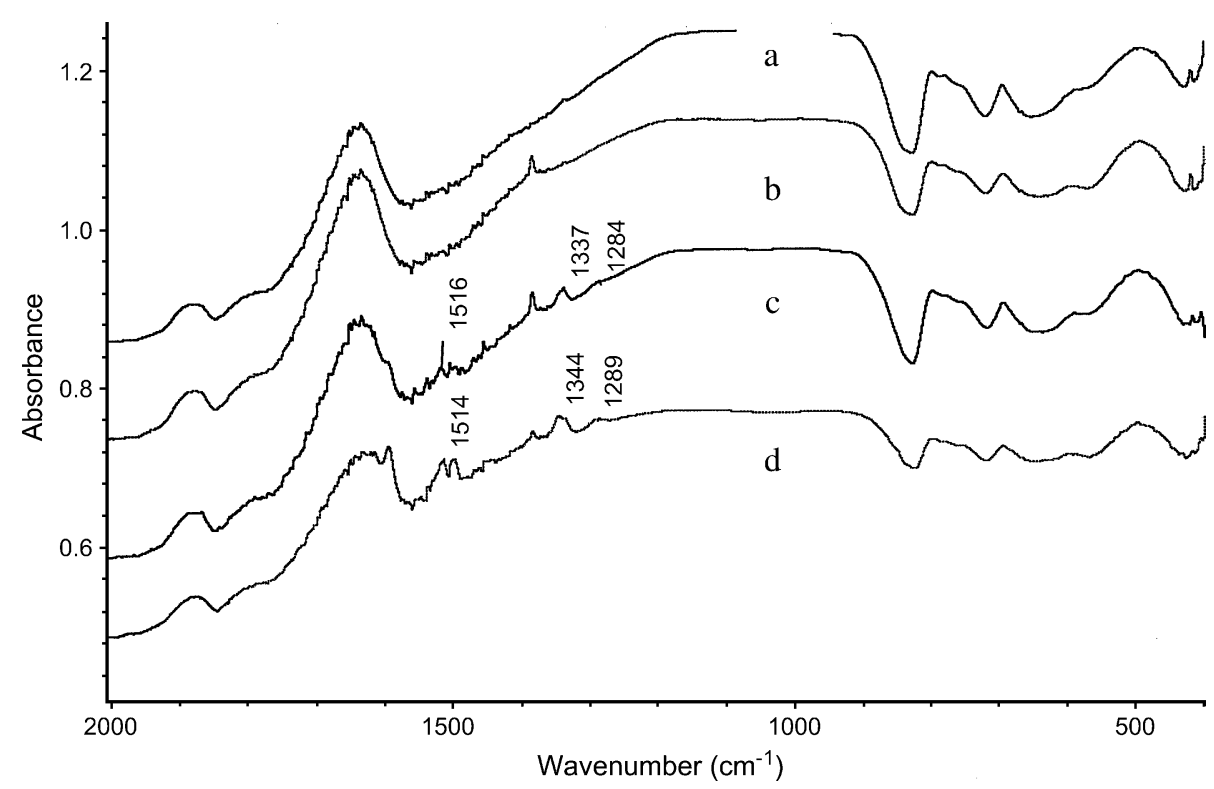

Fig. 5. FTIR spectra of $p$-nitrophenol sorbed on Jiangxi soil in the $2000-600 \mathrm{~cm}^{-1}$ region. (a) dried soil; (b) dried soil-Cu; (c) FTIR spectra of $p$-nitrophenol in aqueous solution on $\mathrm{Cu}$-soil. (d) FTIR spectra of $p$-nitrophenol in $n$-hexane system on $\mathrm{Cu}$-soil. 
vibrational peaks interacting with $\mathrm{Cu}$-exchanged soil can be rationalized in terms of inner-sphere complexation between the $-\mathrm{NO}_{2}$ group and $\mathrm{Cu}$. These data provide molecular-level support for the hypothesis that $p$-nitrophenol sorption on soils is affected, in part, by interactions with cations. The influence of cations on the $-\mathrm{NO}_{2}$ stretching bands is also observed through earlier IR studies of $p$-nitrophenol (Saltzman and Yariv, 1975) and parathion (Saltzman and Yariv, 1976) sorption on montmorillonite.

The changes in $-\mathrm{NO}_{2}$ stretching frequencies for $p$-nitrophenol upon adsorption by $\mathrm{Cu}$-soil suggest that site-specific interactions between $\mathrm{Cu}$ and $-\mathrm{NO}_{2}$ groups may be responsible, in part, for the high affinity of $p$-nitrophenol for soils.

Sorption isotherms of $p$-nitrophenol on two partially hydrated $(10 \%$ water) soils from $n$-hexane are also shown in Fig. 4. Due to the competition of highly polar water for mineral phase surfaces, the presence of $10 \%$ water in soils markedly reduced the adsorption of $p$-nitrophenol. As shown in Fig. 6, the effect of water ratio on the adsorption of $p$-nitrophenol by two soils was conducted at a constant initial $p$-nitrophenol concentration of $0.62 \mathrm{mM}$. The ability of $p$-nitrophenol to be adsorbed from $n$-hexane decreased as the amount of water increased. Most $p$-nitrophenol adsorption had been suppressed when soils were hydrated by $10 \%$ water.

In summary, the adsorption of p-nitrophenol on soils decreased greatly in the presence of $\mathrm{Cu}$ in aqueous system. Infrared spectra indicated that $p$-nitrophenol sorbed by soils coordinated with metal cation directly in $n$-hexane system. In the aqueous system, the larger hydration sphere of copper shrunk the size of the effective adsorption domains. Furthermore, the high acid strength of the $-\mathrm{OH}$ group of $p$-nitrophenol does not favor the formation of $\mathrm{H}$-bond with water associated copper because the highly

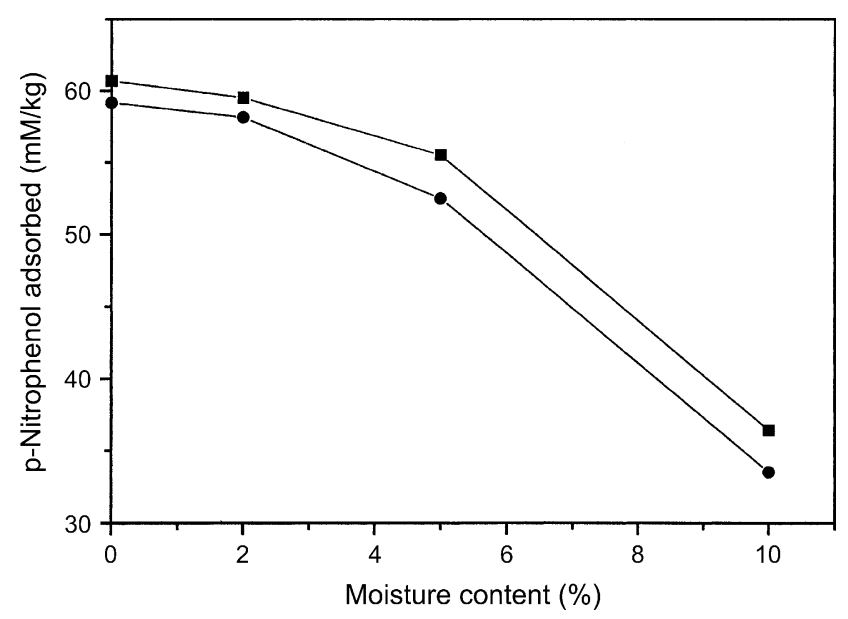

Fig. 6. Effect of moisture content on the adsorption of $p$-nitrophenol by (ם) Heilongjiang soil; ( $)$ Jiangxi soil. polarizing heavy metal increase the ability of donoring proton.

\section{Acknowledgement}

This work was funded by the National Natural Science Foundation of China (grant number 20237010 and 20377048) and the National Basic Research Program (2003CB415004).

\section{References}

Banat, F.A., Al-Bashir, B., Al-Asheh, S., Hayajneh, O., 2000. Adsorption of phenol by bentonite. Environ. Pollut. 107, 391-398.

Boyd, S.A., Sheng, G., Teppen, B.J., Johnston, C.T., 2001. Mechanisms for the adsorption of substituted nitrobenzenes by smectite clays. Environ. Sci. Technol. 35, 4227-4234.

Düring, R.A., Hoß, T., Gäth, S., 2003. Sorption and bioavailability of heavy metals in long-term differently tilled soils amended with organic wastes. Sci. Total Environ. 313, 227-234.

Gimsing, A.L., Borggaard, O.K., Bang, M., 2004a. Influence of soil composition on adsorption of glyphosate and phosphate by contrasting Danish surface soils. Eur. J. Soil Sci. 55, 183-191.

Gimsing, A.J., Borggaard, O.K., Sestoft, P., 2004b. Modeling the kinetics of the competitive adsorption and desorption of glyphosate and phosphate on goethite and gibbsite and in soils. Environ. Sci. Technol. 38, 1718-1722.

Haderlein, S.B., Schwarzenbach, R.P., 1993. Adsorption of substituted nitrobenzenes and nitrophenols to mineral surfaces. Environ. Sci. Technol. 27, 316-326.

Haderlein, S.B., Weissmahr, K.W., Schwarzenbach, R.P., 1996. Specific adsorption of nitroaromatic explosives and pesticides to clay minerals. Environ. Sci. Technol. 30, 612-622.

Johnston, C.T., De Oliveira, M.F., Teppen, B.J., Sheng, G., Boyd, S.A., 2001. Spectroscopic study of nitroaromatic-smectite sorption mechanisms. Environ. Sci. Technol. 35, 4767-4772.

Johnston, C.T., Sheng, G., Teppen, B.J., Boyd, S.A., Oliveira, M.F., 2002. Spectroscopic study of dinitrophenol herbicide sorption on smectite. Environ. Sci. Technol. 36, 5067-5074.

Laird, D.A., Fleming, P.D., 1999. Mechanisms for adsorption of organic bases on hydrated smectite surfaces. Environ. Toxicol. Chem. 18, 1668-1672.

Li, H., Sheng, G., Teppen, B.J., Johnston, C.T., Boyd, S.A., 2003. Sorption and desorption of pesticides by clay minerals and humic acid-clay complexes. Soil Sci. Soc. Am. J. 67, 122-131.

Liu, A., Richard, D., 2000. Gonzalez modeling adsorption of copper (II), cadmium (II) and lead (II) on purified humic acid. Langmuir 16, 3902-3909.

Maqueda, C., Undabeytia, T., Morillo, E., 1998. Retention and release of copper on montmorillonite as affected by the presence of a pesticide. J. Agric. Food Chem. 46, 1200-1204.

McKeague, J.A., Day, J.H., 1966. Dithionite- and oxalate-extractable $\mathrm{Fe}$ and $\mathrm{Al}$ as aids in different various classes of soils. Can. J. Soil Sci. 46, 13-22.

Morillo, E., Maqueda, C., Bejarano, M., Madrid, L., Undabeytia, T., 1994. Cu (II)-glyphosate system: a study by anodic stripping voltammetry and the influence on $\mathrm{Cu}$ adsorption by montmorillonite. Chemosphere 28, 2185-2196.

Morillo, E., Undabeytia, T., Maqueda, C., 1997. Adsorption of glyphosate on the clay mineral montmorillonite: effect of $\mathrm{Cu}$ (II) in solution and adsorbed on the mineral. Environ. Sci. Technol. 31, 3588-3592.

Morillo, E., Undabeytia, T., Maqueda, C., Ramos, A., 2000. Glyphosate adsorption on soils of different characteristics: influence of copper addition. Chemosphere 40, 103-107. 
Morillo, E., Undabeytia, T., Maqueda, C., Ramos, A., 2002. The effect of dissolved glyphosate upon the sorption of copper by three selected soils. Chemosphere 47, 747-752.

Mulligan, C.N., Yong, R.N., Gibbs, B.F., James, S., Bennett, H.P.J., 1999. Metal removal from contaminated soil and sediments by the biosurfactant surfactin. Environ. Sci. Technol. 33, 3812-3820.

Nelson, D.W., Sommers, L.E., 1982. Total carbon, organic carbon, and organic matter. In: Page, A.L. (Ed.), Methods of Soil Analysis Part 2. Chemical and Microbiological Properties, second ed. American Society of Agronomy, Madison, WI, pp. 539-579.

Plemenschikov, A., Leszczynski, J., 1999. Adsorption of 1,3,5trinitrobenzene on the siloxane sites of clay minerals: $a b$ initio calculations of molecular models. J. Phys. Chem. B 103, 6886-6890.

Pusino, A., Fiori, M.G., Braschi, I., Gessa, C., 2003. Adsorption and desorption of triasulfuron by soil. J. Agric. Food Chem. 51, $5350-5354$

Pusino, A., Petretto, S., Gessa, C., 2004. Sorption of primisulfuron on soil, and inorganic and organic soil colloids. Eur. J. Soil Sci. 55, $175-182$.

Saltzman, S., Yariv, S., 1975. Infrared study of the sorption of phenol and $p$-nitrophenol by montmorillonite. Soil Sci. Soc. Am. Proc. 39, 474-479.
Saltzman, S., Yariv, S., 1976. Infrared and X-ray study of parathionmontmorillonite sorption complexes. Soil Sci. Soc. Am. J. 40, $34-38$.

Sheng, G., Johnston, C.T., Teppen, B.J., Boyd, S.A., 2002. Adsorption of dinitrophenol herbicides from water by montmorillonites. Clays Clay Miner. 50, 25-34.

Shuman, L.M., 1982. Separating soil iron- and manganese-oxide fractions for microelement analysis. Soil Sci. Soc. Am. J. 46, 1099-1102.

Weissmahr, K.W., Haderlein, S.B., Schwarzenbach, R.P., 1998. Complex formation of soil minerals with nitroaromatic explosives and other $\pi$-acceptors. Soil Sci. Soc. Am. J. 62, 369-378.

Weissmahr, K.W., Haderlein, S.B., Schwarzenbach, R.P., 1997. In situ spectroscopic investigations of adsorption mechanisms of nitroaromatic compounds at clay minerals. Environ. Sci. Technol. 31, 240-247.

Weissmahr, K.W., Hildenbrand, M., Schwarzenbach, R.P., Haderlein, S.B., 1999. Laboratory and field scale evaluation of geochemical controls on groundwater transport of nitroaromatic ammunition residues. Environ. Sci. Technol. 33, 2593-2600.

Zhu, L., Chen, B., Shen, X., 2000. Sorption of phenol, p-nitrophenol, and aniline to dual-cation organobentonites from water. Environ. Sci. Technol. 34, 468-475. 